\title{
Is Function-Based Resection Using Intraoperative Awake Brain Mapping Feasible and Safe for Solitary Brain Metastases Within Eloquent Areas?
}

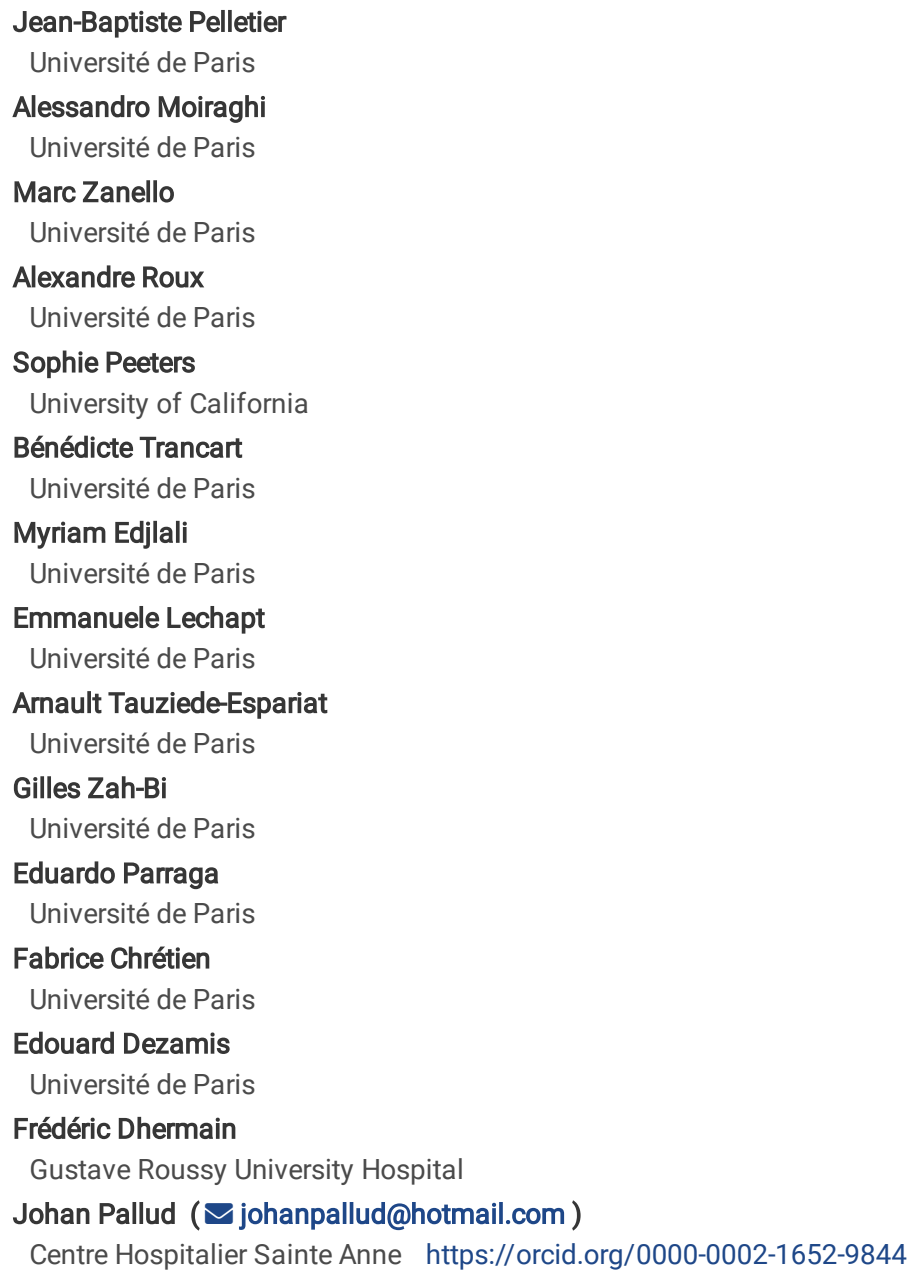

Original Article

Keywords: Awake surgery, Brain metastasis, Extent of resection, Feasibility, Intraoperative brain mapping, Safety

Posted Date: February 4th, 2021

DOI: https://doi.org/10.21203/rs.3.rs-171367/v1

License: @) (7) This work is licensed under a Creative Commons Attribution 4.0 International License. Read Full License

Version of Record: A version of this preprint was published at Neurosurgical Review on March 4th, 2021. See the published version at https://doi.org/10.1007/s10143-021-01504-6. 


\section{Abstract}

Objective

To assess feasibility and safety of function-based resection under awake conditions for solitary brain metastasis patients.

Methods

Retrospective, observational, single-institution case-control study (2014-2019). Inclusion criteria: adult patients, solitary brain metastasis, supratentorial location within eloquent areas, function-based awake resection. Case matching (1:1) criteria between metastasis group and control group (high-grade gliomas): sex, tumor location, tumor volume, preoperative Karnofsky Performance Status score, age, educational level.

Results

Twenty patients were included. Intraoperatively, all patients were cooperative, no obstacles precluded procedure from being performed. A positive functional mapping was achieved at both cortical and subcortical levels, allowing for a function-based resection in all patients. The case-matched analysis showed that intraoperative and postoperative events were similar, except for a shorter duration of the surgery $(p<0.001)$ and of the awake phase $(p<0.001)$ in the metastasis group. A total resection was performed in 18 cases ( $90 \%$, including 10 supramarginal resections), and a partial resection was performed in two cases $(10 \%)$. At three months postoperative months, none of the patients had worsening of their neurological condition or uncontrolled seizures, three patients had an improvement in their seizure control, and seven patients had a Karnofsky Performance Status score increase $\geq 10$ points.

Conclusions

Function-based resection under awake conditions preserving the brain connectivity is feasible and safe in the specific population of solitary brain metastasis patients and allows for high resection rates within eloquent brain areas while preserving the overall and neurological condition of the patients. Awake craniotomy should be considered to optimize outcomes in brain metastases in eloquent areas.

\section{Introduction}

The surgical resection of brain metastases aims to : 1) provide the histo-molecular diagnosis and/or characterize a molecular anomaly for a targeted therapy[11]; 2) discriminate between radiation-induced changes (the so-called radionecrosis) and tumor recurrence in cases of previous radiotherapy[26]; 3) reduce symptoms of intracranial hypertension, focal neurological deficits, and seizures, and allow for a rapid steroid taper[24]; and 4) improve local tumor control and overall survival in case of a solitary metastasis, particularly in the setting of a large tumor, a cystic or necrotic tumor, and/or a cortico-subcortical tumor topography considering the low efficacy and potential adverse effects of stereotactic radiotherapy in these situations[11].

The surgical resection of brain metastases located in eloquent areas remains a particular challenge due to the higher risk of postoperative neurological and neurocognitive deficits[5, 21]. It is a crucial issue since survival is linked to both the extent of resection and the functional status of the patient[21]. Intraoperative functional brain mapping under awake surgery $[3,6,12,14,20]$ has potential advantages: 1) safe approach to the metastasis through the identification of eloquent cortico-subcortical connectivity[7, 17]; 2) resection according to functional connectivity and beyond the limits of the metastasis[10]; 3 ) better control of the surgical risks regarding metastases initially deemed inoperable and previously treated with stereotactic radiotherapy for which a histomolecular diagnosis is required. Previous series have reported awake surgery for brain metastases[7, 9, 10, 21]. Two pioneer studies from Dusseldorf reported that awake surgery is feasible for metastases in eloquent areas, minimizing postoperative neurologic deficits and morbidity and permitting supramarginal resection[9, 10]. They suggested that awake craniotomy should be considered as a technique to optimize outcomes in brain metastases in eloquent areas.

The aim of the present study was to find out whether patients harboring a solitary brain metastasis located in eloquent areas can be operated safely with the aid of awake surgery techniques. We assessed intraoperative findings, neurological and neurocognitive assessments, and ability to work following functionbased maximal surgical resection attempts according to functional boundaries using intraoperative cortico-subcortical mapping under awake conditions in adult patients harboring a solitary brain metastasis within eloquent cortical and subcortical regions. In order to assess the efficacy and safety of awake surgery in the specific population of solitary brain metastasis patients, we performed a case-matched analysis with a control group of patients operated on with the same surgical technique for a high-grade diffuse glioma.

\section{Materials And Methods}

\section{Study design and setting}

This retrospective, observational study was conducted at a tertiary referral neurosurgical center for brain tumors (January 2014 - December 2019). This study received approval (IRB\#1: 2020/10) from the institutional review board (IRB00011687).

\section{Awake metastasis group selection}

Inclusion criteria were: 1) $\geq 18$ years; 2) solitary brain metastasis of non-neurogenic origin; 3) supratentorial tumor location within eloquent areas as previously defined[22]; 4) function-based resection with intraoperative cortico-subcortical mapping under awake conditions.

Four hundred twenty-three brain metastases in adult patients were operated on over the study period, 98 being located within eloquent areas. From the 98 metastases located within eloquent areas and surgically treated, 31 were excluded due to multiples brain metastases. From the 67 solitary metastases located 
within eloquent areas and surgically treated, 47 were operated on using asleep surgery without any functional mapping due to neurosurgeon's preference in 39 cases and due to contraindication to awake surgery in eight cases. We finally included 20 solitary metastases located within eloquent areas and operated on using intraoperative cortico-subcortical mapping under awake conditions ( $20.4 \%$ of eloquent brain metastases, $4.7 \%$ of the whole series).

\section{Awake control group selection}

In order to assess the safety of awake surgery in the specific condition of solitary brain metastasis patients, we performed a case-matched analysis with a control group of patients harboring a different disease i.e., a high-grade glioma, and having operated on with the same surgical technique. All patients who underwent function-based resection for a high-grade glioma using the same surgical technique and during the same time period were screened. Each patient in the awake metastasis group was individually matched with a control patient according to the following criteria, listed in order of importance: 1) sex; 2) tumor location (same lobe, same side) ; 3) preoperative volume (within $25 \mathrm{~cm}^{3}$ ); 4) preoperative Karnofsky Performance Status (KPS) score (within 10 points); 5) age (within 5 years); and 6) same level of education (estimated using the Barbizet and Duizabo scale[2]). If no control matched in all five criteria, then sex, degree of education within one level, preoperative tumor volume of up to $50 \mathrm{~cm}^{3}$, preoperative KPS score of up to 20 points, or a difference in age of $>5$ years was accepted, in that order of preference. Table 1 shows the characteristics of each matched pair.

\section{Variables and data sources}

Patient-, surgery-, and tumor-related characteristics included: sex, age, previous oncological treatment, clinical sign(s) (increased intracranial pressure, focal neurological deficit, neurocognitive deficit, epileptic seizure), preoperative seizure control, KPS score, tumor location, tumor volume, duration of surgery, intraoperative seizure, current intensity for intraoperative mapping, extent of resection, histo-molecular diagnosis, early postoperative seizure, early postoperative neurological status, early postoperative KPS score, duration of hospital stay, postoperative complications, mode of discharge, three-month seizure control, three-month neurological outcomes, and three-month KPS score.

The tumor volume $\left(\mathrm{cm}^{3}\right)$ was calculated using manual segmentation of abnormal signal on post-contrast T1-weighted sequence by three blinded investigators (JBP, AM, and JP). The extent of resection was quantified on early postoperative MRI (within 48 hours) by manual segmentation of volume of residual tumor and of surgical cavity on post-contrast volumetric T1-weighted sequence by the same three blinded investigators. A supramarginal resection was defined as the complete removal of abnormal signal on post-contrast T1-weighted sequence plus the volume of the postoperative cavity being larger than the preoperative tumor volume as previously defined[19].

Language and neurocognitive functions were tested by a senior speech therapist before and after resection. The tests used are summarized in Supplementary Table 1. For each neurocognitive test, raw scores were converted to standardized scores using normative data that adjust for age, education, sex, ethnicity, and handedness, as appropriate. Before surgery, neurocognitive impairment on each test was defined as a standardized score $\geq 1.5$ Standard Deviations below the normative mean. Postoperatively, declines or improvements in neurocognitive test performance were defined by using the Reliable Change Index. All Reliable Change Index thresholds were rounded to the nearest whole number. Changes that did not meet the Reliable Change Index criteria for decline or improvement were classified as stable.

\section{Surgical procedure}

Intraoperative functional mapping was performed using our in-house "asleep-awake-asleep" protocol[17, 28]. Functional mapping was conducted by direct electrical stimulation using a bipolar electrode (5-mm space between tips, biphasic current, pulse frequency of $60 \mathrm{~Hz}$; pulse phase duration of $1 \mathrm{~ms}$; Osiris NeuroStimulator, Inomed). Non-eloquent areas were identified to perform the corticectomy directed toward the metastasis, with assistance from intraoperative MRI-based neuronavigation and ultrasonography. To control for neurological and cognitive function, intraoperative tasks were performed, including motor network, somatosensory network, language, calculation, memory or even visuospatial processing, semantic cognition ( $p y r a m i d$ and palm tree test), and social cognition (modified version of the reading the mind in the eyes test), depending on glioma location and according to practical guidelines, [8, 16, 17]. The patient was monitored by continuous execution of the required tasks throughout the metastasis resection and the types of disturbances were classified by a senior speech therapist. The metastasis was resected en bloc, whenever possible, by alternating dissection and stimulation for subcortical functional mapping at the tumor wall and at the periphery of the metastasis. In all patients, repeated ultrasonography was performed throughout the resection to control for anatomical landmarks. Each subcortical anatomical site inducing the same and reproducible functional impairment on three trials was considered as "eloquent" and was marked with a sterile numbered tag, were located and registered using MRI-based neuronavigation system, and intraoperative photographs were performed at the end of the resection. Resections were stopped when eloquent subcortical structures defining the deep functional boundaries were identified intraoperatively using dedicated intraoperative tasks within the surgical cavity with no security margin of brain tissue left around the functional connectivity or until the patient felt too tired to work efficiently.

\section{Statistical analyses}

Descriptive statistics were given as the mean \pm standard deviation for continuous variables and as a percentage for categorical variables. Univariate analyses were carried out using the chi-square or Fisher's exact tests for comparing categorical variables, and the unpaired t-test or Mann-Whitney rank sum test for continuous variables, as appropriate. A p-value of less than 0.05 was considered significant. Analyses were performed using JMP 14.1.0 (SAS Institute Inc, Cary, North Carolina, USA).

\section{Results}

\section{Patient characteristics}


Twenty patients (60.5\% men, mean age 55.6 \pm 11.4 -year-old) were included. Clinical and imaging characteristics are detailed in Table 2.

There were no significant differences between the metastasis and control groups in sex ratio, age, education, increased intracranial pressure, focal neurological deficit, seizure control, KPS score, tumor location, and tumor volume. There were fewer seizures (50\% vs. $85 \%$, $p=0.016)$ and more previous oncological treatments before surgery $(70 \%$ Vs. $15 \%, p<0.001)$ in the metastasis group than in the control group.

\section{Awake surgery}

Intraoperative characteristics are detailed in Table 3. All patients were cooperative, there were no obstacles that precluded a function-based resection from being performed (no intraoperative seizures, postural pain in 10\%). Intraoperatively, positive functional mapping was achieved in all patients at both cortical and subcortical levels (mean stimulation current intensity $3.6 \pm 0.9 \mathrm{~mA}$ ). The overall duration of the surgery $(181.2 \pm 34.7$ versus $237.6 \pm 38.2$ min, $p<0.001)$ and the duration of the awake phase $(63.2 \pm 23.3$ versus $96.4 \pm 18.2 \mathrm{~min}, \mathrm{p}<0.001)$ were significantly shorter in the metastasis group than in the control group.

A total resection was performed in 18 cases ( $90 \%$, including 10 cases $(50 \%)$ of supramarginal resection), and a partial resection was performed in the remaining two cases (10\%, two radionecrosis). In all cases, resection was pursued until eloquent subcortical pathways were identified, including in the two cases with partial resection, as illustrated in Figure 1.

\section{Postoperative outcomes}

In the early postoperative period, clinical worsening occurred in five cases $(25 \%)$, seizures occurred in two cases (10\%), KPS score decreased at $76.5 \pm 10.9$, surgical site infection occurred in two cases (10\%), medical complications occurred in three cases (15\%, two urinary tract infections, one hemoptysis). Eighteen patients (90\%) were discharged home. The length of hospital stay was similar in the metastasis and in the control groups (median 9 vs. 8 days, $p=0.118$ ) with a 240-day-long hospital stay for a postoperative infection in one metastatic patient. All patients underwent personalized rehabilitation. The 15 patients with a histologically confirmed metastasis received postoperative focal radiotherapy whereas the five patients with radionecrosis had no further focal treatment.

The evolution of the clinical and neurocognitive statuses before and after awake surgery are detailed in Table 4. At three postoperative months, two patients had died from the systemic evolution of their neoplasm. As compared to the preoperative evaluation, none of the patients had worsening of their neurological condition or uncontrolled seizures, three patients had an improvement in their seizure control, and seven patients had a KPS score increase $\geq 10$ points.

A postoperative neurocognitive evaluation has been performed in nine cases (45\%) at a mean $200 \pm 50$ days (nine patients had a neoplasm evolution precluding the evaluation to be performed and two patients declined the evaluation). Two patients (22.2\%) improved, five patients (55.6\%) remained stable, and two patients $(22.2 \%)$ worsened as compared to the preoperative neurocognitive evaluation.

\section{Discussion}

\section{Key results}

In this case-matched analysis of 20 adult patients harboring a brain metastasis within eloquent regions and undergoing a function-based resection under awake conditions, we show that: 1) there were no obstacles precluding function-based resection from being performed in all patients; 2) there were no major differences in the feasibility of the awake procedure between metastasis patients and high-grade gliomas patients; 3 ) the function-based resection was total in 18 cases ( $90 \%$, including 10 cases of supramarginal resection), and partial in two cases $(10 \%) ; 4)$ at three months postoperative, none of the patients had worsening of their neurological condition or uncontrolled seizures, seven patients had a KPS score increase $\geq 10$ points compared to the preoperative evaluation; and 5) on postoperative neurocognitive evaluation, available in nine cases, $22.2 \%$ of patients improved, $55.6 \%$ of patients remained stable, and $22.2 \%$ of patients worsened compared to the preoperative neurocognitive evaluation.

\section{Interpretation}

We provide a detailed case-matched analysis of intraoperative findings between function-based resection under awake conditions of brain metastases and the well-established technique applied for high-grade gliomas. Despite the presence of previous oncological treatments before awake surgery in $75 \%$ of patients from the metastasis group, we did not find increase in technical difficulties and complications compared to the control group. Particularly, a function-based resection according to functional boundaries was achieved in all patients. We report similar complication rates compared to previous published series[7, 21]. Kamp et al. studied the safety of awake resection for metastases in eloquent brain areas: they reported a series of supramarginal resections with no difference in median National Institute of Health Stroke Scale between the pre- and postoperative evaluations and no new permanent neurological deficits after surgery[9]. The present data suggest that function-based resection using awake brain mapping is a safe and effective tool to remove brain metastases within eloquent areas[5, 9, 21]. The expertise accumulated from glioma resection could be easily transferred in selected metastasis patients[17].

We reported $25 \%$ of clinical worsening in the early postoperative period, no new permanent neurological deficits, and no uncontrolled seizures at three months postoperative as well as stable KPS scores despite postoperative adjuvant oncological treatments. A systematic review by Chua et al., analyzing 104 patients from seven studies undergoing awake craniotomy for a metastasis, reported $27 \%$ of persistent or worsened neurological deficits in the early postoperative period and reported $1 \%$ of permanent neurological deficits at follow-up[5]. Sanmillan et al., in a series of 31 patients operated on for a brain metastasis within eloquent areas using awake functional mapping or asleep monitoring (evoked potentials), reported that patients who had a worsened clinical outcome postoperatively had a shorter overall survival, the postoperative KPS score being a strong predictor[21]. The completion of postoperative cognitive evaluations was limited by the tumor evolution; we observed, in the nine available cases, stable and improved cognitive functions in $56 \%$, and $22 \%$ of cases, respectively, 
compared to the preoperative neurocognitive evaluation despite the application of postoperative oncological treatments. Other studies have demonstrated a similar relationship between functional status and survival[1, 13,23, 25]. Similarly, the present study suggests that intraoperative functional mapping under awake conditions allows for both a safe and large resection of metastases in eloquent brain areas, which may be associated with survival benefits.

The extent of resection is a crucial component of achieving local control[4, 18] since most brain metastases display an irregular tumor-brain interface at a microscopic scale[15]. Supramarginal resection aims to improve local control[27] by removing the peripheral brain parenchyma possibly containing scarse tumor cells. Here, the $50 \%$ rate of supramaximal resection supports awake resection as a useful technical adjunct to improve local control of brain metastases within eloquent areas. Of note, a function-based partial resection has been performed in two cases where subcortical functional mapping identified eloquent pathways embedded within a radionecrosis. This is of particular interest in situations of metastases previously treated by radiotherapy, where radiationinduced changes can be nested within eloquent areas, to minimize surgical risks.

\section{Generalizability}

To control for selection biases in the assessment of the safety of awake surgery in the specific condition of solitary brain metastasis patients, we performed a case-matched analysis with a control group of patients operated on using the same surgical technique for a high-grade diffuse glioma. Previous studies limited their analysis to the gross total resection or reported a subjective intraoperative evaluation of the supramarginal resection[5, 10, 27]. The present study controlled for this bias by quantifying the extent of resection on early postoperative MRI.

\section{Limitations}

These findings should be interpreted with caution, given the exploratory and retrospective design of the study, the small sample size including patients with different primary neoplasms, and data missing for $55 \%$ of postoperative cognitive evaluations. Inclusion biases may limit the generalizability to the overall population of adult patients with metastases within eloquent brain areas. A prospective data collection would be necessary to better assess neurocognitive outcomes.

\section{Conclusions}

Function-based resection under awake conditions preserving the brain connectivity is feasible and safe in the specific population of solitary brain metastasis patients and allows for high rates of total resection for metastases within eloquent brain areas while preserving the overall and neurological condition of the patients. Awake craniotomy should be considered as a possible surgical technique to optimize outcomes in brain metastases in eloquent areas.

\section{Declarations}

Previous Presentations: there have been no presentations of this data.

Funding: no funding was provided for this study.

Conflict of interest: the authors have no conflict of interest to disclose.

Ethics approval: This study received approval (IRB\#1: 2020/10) from the institutional review board (IRB00011687).

Consent to participate: Due to the retrospective nature of the study no consent was obtained.

Consent for publication: Due to the retrospective nature of the study no consent was obtained.

Availability of data and material: not applicable.

Code availability: not applicable.

\section{Author contribution:}

JBP, AM, BT, ME, EL, ATE, ED, and JP did the data collection.

JBP, AM, and JP did the data analysis.

JBP, AM, MZ, AR, SP, BT, ME, EL, ATE, GZB, EP, FC, ED, FD, and JP did the data interpretation.

JBP, AM, SP, and JP wrote the report.

JBP, AM, MZ, AR, SP, BT, ME, EL, ATE, GZB, EP, FC, ED, FD, and JP reviewed and approved the paper.

\section{Acknowledgments}

The authors gratefully acknowledge (in alphabetical order): the surgical neuro-oncology team, and particularly Alissia Basquin-Sanz, Odile Rigaux-Viodé, and Sylvie Sicot; the department of Neurosurgery; the department of Neuropathology, and particularly Pascale Varlet; the department of Neuroradiology, and particularly Joseph Benzakoun, Olivier Naggara, Catherine Oppenheim and Jean-François Meder; the department of Neurophysiology, and particularly Martine Gavaret and Angela Marchi; the department of neuro-anaesthesia and neuro-intensive care, and particularly Abderrezak Akhrouf, Roland Benichou, Serge Biou, 
Mathieu Daniel, Hortense Dumontier, Aurélie Gruner, Aurélien Mazeraud, Alain Monpetit, Xavier Sauvageon, Caroline Schimpf, Alain Sermet, Tarek Sharshar, and Gilles Thouvenot; the neuro-oncology unit of the Gustave Roussy University Hospital, Villejuif, France, and particularly Sarah Dumont.

\section{References}

1. Arita H, Narita Y, Miyakita Y, Ohno M, Sumi M, Shibui S (2014) Risk factors for early death after surgery in patients with brain metastases: Reevaluation of the indications for and role of surgery. J Neurooncol. doi: 10.1007/s11060-013-1273-5

2. Barbizet J, Duizabo $P$ (1985) Abrégés de médecine. Neuropsychologie, 3ème éditi. Masson

3. De Benedictis A, Moritz-Gasser S, Duffau H (2010) Awake mapping optimizes the extent of resection for low-grade gliomas in eloquent areas. Neurosurgery. doi: 10.1227/01.NEU.0000369514.74284.78

4. Brown PD, Ballman K V, Cerhan JH, et al (2017) Postoperative stereotactic radiosurgery compared with whole brain radiotherapy for resected metastatic brain disease (NCCTG N107C/CEC.3): a multicentre, randomised, controlled, phase 3 trial. Lancet Oncol 18(8):1049-1060

5. Chua TH, See AAQ, Ang BT, King NKK (2018) Awake Craniotomy for Resection of Brain Metastases: A Systematic Review. World Neurosurg 120:e1128e1135

6. Duffau H (2018) Diffuse low-grade glioma, oncological outcome and quality of life: A surgical perspective. Curr Opin Oncol. doi: $10.1097 / \mathrm{CC} 0.0000000000000483$

7. Groshev A, Padalia D, Patel S, Garcia-Getting R, Sahebjam S, Forsyth PA, Vrionis FD, Etame AB (2017) Clinical outcomes from maximum-safe resection of primary and metastatic brain tumors using awake craniotomy. Clin Neurol Neurosurg 157:25-30

8. Herbet G, Rigaux-Viodé O, Moritz-Gasser S (2017) Peri- and intraoperative cognitive and language assessment for surgical resection in brain eloquent structures. Neurochirurgie. doi: 10.1016/j.neuchi.2016.10.011

9. Kamp MA, Dibué M, Niemann L, Reichelt DC, Felsberg J, Steiger H-J, Szelényi A, Rapp M, Sabel M (2012) Proof of principle: supramarginal resection of cerebral metastases in eloquent brain areas. Acta Neurochir (Wien) 154(11):1981-1986

10. Kamp MA, Rapp M, Slotty PJ, Turowski B, Sadat H, Smuga M, Dibué-Adjei M, Steiger H-J, Szelényi A, Sabel M (2015) Incidence of local in-brain progression after supramarginal resection of cerebral metastases. Acta Neurochir (Wien) 157(6):905-911

11. Metellus P, Pallud J, Ram Z, Watts C, Westphal M (2020) Surgery in Brain Metastasis Management: Therapeutic, Diagnostic, and Strategic Considerations. Cent. Nerv. Syst. Metastases. Springer International Publishing, Cham, pp 183-190

12. Meyer FB, Bates LM, Goerss SJ, Friedman JA, Windschitl WL, Duffy JR, Perkins WJ, O'Neill BP (2001) Awake craniotomy for aggressive resection of primary gliomas located in eloquent brain. Mayo Clin Proc. doi: 10.4065/76.7.677

13. Mintz A, Perry J, Spithoff K, Chambers A, Laperriere N (2007) Management of single brain metastasis: A practice guideline. Curr Oncol. doi: $10.3747 /$ co.2007.129

14. Muto J, Dezamis E, Rigaux-Viode O, et al (2018) Functional-Based Resection Does Not Worsen Quality of Life in Patients with a Diffuse Low-Grade Glioma Involving Eloquent Brain Regions: A Prospective Cohort Study. World Neurosurg. doi: 10.1016/j.wneu.2018.01.213

15. Neves S, Mazal PR, Wanschitz J, Rudnay AC, Drlicek M, Czech T, Wüstinger C, Budka H (2001) Pseudogliomatous growth pattern of anaplastic small cell carcinomas metastatic to the brain. Clin. Neuropathol.

16. Pallud J, Mandonnet E, Corns R, Dezamis E, Parraga E, Zanello M, Spena G (2017) Technical principles of direct bipolar electrostimulation for cortical and subcortical mapping in awake craniotomy. Neurochirurgie. doi: 10.1016/j.neuchi.2016.12.004

17. Pallud J, Rigaux-Viode O, Corns R, Muto J, Lopez Lopez C, Mellerio C, Sauvageon X, Dezamis E (2017) Direct electrical bipolar electrostimulation for functional cortical and subcortical cerebral mapping in awake craniotomy. Practical considerations. Neurochirurgie 63(3):164-174

18. Patchell RA, Tibbs PA, Walsh JW, Dempsey RJ, Maruyama Y, Kryscio RJ, Markesbery WR, Macdonald JS, Young B (1990) A Randomized Trial of Surgery in the Treatment of Single Metastases to the Brain. N Engl J Med 322(8):494-500

19. Rossi M, Ambrogi F, Gay L, et al (2019) Is supratotal resection achievable in low-grade gliomas? Feasibility, putative factors, safety, and functional outcome. J Neurosurg 132(June):1-14

20. Sanai N, Mirzadeh Z, Berger MS (2008) Functional Outcome after Language Mapping for Glioma Resection. N Engl J Med 358(1):18-27

21. Sanmillan JL, Fernández-Coello A, Fernández-Conejero I, Plans G, Gabarrós A (2017) Functional approach using intraoperative brain mapping and neurophysiological monitoring for the surgical treatment of brain metastases in the central region. J Neurosurg 126(3):698-707

22. Sawaya R, Hammoud M, Schoppa D, Hess KR, Wu SZ, Shi W-M, Wildrick DM (1998) Neurosurgical Outcomes in a Modern Series of 400 Craniotomies for Treatment of Parenchymal Tumors. Neurosurgery 42(5):1044-1055

23. Schackert G, Lindner C, Petschke S, Leimert M, Kirsch M (2013) Retrospective study of 127 surgically treated patients with multiple brain metastases: Indication, prognostic factors, and outcome. Acta Neurochir (Wien). doi: 10.1007/s00701-012-1606-8

24. Soffietti R, Abacioglu U, Baumert B, et al (2017) Diagnosis and treatment of brain metastases from solid tumors: Guidelines from the European Association of neuro-oncology (EANO). Neuro Oncol 19(2):162-174

25. Soffietti R, Cornu P, Delattre JY, et al (2006) EFNS Guidelines on diagnosis and treatment of brain metastases: Report of an EFNS Task Force. Eur J Neurol. doi: 10.1111/j.1468-1331.2006.01506.x

26. Telera S, Fabi A, Pace A, Vidiri A, Anelli V, Carapella CM, Marucci L, Crispo F, Sperduti I, Pompili A (2013) Radionecrosis induced by stereotactic radiosurgery of brain metastases: Results of surgery and outcome of disease. J Neurooncol. doi: 10.1007/s11060-013-1120-8 
27. Yoo H, Kim YZ, Nam BH, Shin SH, Yang HS, Lee JS, Zo J II, Lee SH (2009) Reduced local recurrence of a single brain metastasis through microscopic total resection: Clinical article. J Neurosurg 110(4):730-736

28. Zanello M, Roux A, Zah-Bi G, et al (2020) Predictors of early postoperative epileptic seizures after awake surgery in supratentorial diffuse gliomas. J Neurosurg. doi: 10.3171/2020.1.jns192774

\section{Tables}

Table 1. Metastasis and control group paired by matching criteria.

\begin{tabular}{|c|c|c|c|c|c|c|c|c|c|c|c|c|c|c|}
\hline \multirow[t]{2}{*}{ Patient } & \multicolumn{7}{|c|}{ Metastasis group } & \multicolumn{7}{|c|}{ Control group } \\
\hline & $\begin{array}{l}\text { Age } \\
\text { (year) }\end{array}$ & Lobe & Side & $\begin{array}{l}\text { Volume } \\
\left(\mathrm{cm}^{3}\right)\end{array}$ & $\begin{array}{l}\text { KPS } \\
\text { Score }\end{array}$ & Sex & $\begin{array}{l}\text { Education } \\
\text { level }\end{array}$ & $\begin{array}{l}\text { Age } \\
\text { (year) }\end{array}$ & Lobe & Side & $\begin{array}{l}\text { Volume } \\
\left(\mathrm{cm}^{3}\right)\end{array}$ & $\begin{array}{l}\text { KPS } \\
\text { score }\end{array}$ & Sex & $\begin{array}{l}\text { Education } \\
\text { level }\end{array}$ \\
\hline \multicolumn{15}{|c|}{ Complete match } \\
\hline 20 & 43 & $\mathrm{P}$ & L & 4.2 & 80 & $M$ & 7 & 42 & $\mathrm{P}$ & $\mathrm{L}$ & 2.0 & 90 & $M$ & 7 \\
\hline 7 & 43 & $\mathrm{P}$ & L & 7.4 & 80 & $\mathrm{~F}$ & 7 & 40 & $\mathrm{P}$ & $\mathrm{L}$ & 11.6 & 80 & $\mathrm{~F}$ & 7 \\
\hline 17 & 52 & $\mathrm{~T}$ & L & 6.2 & 90 & $\mathrm{~F}$ & 4 & 47 & $\mathrm{~T}$ & $\mathrm{~L}$ & 3.1 & 90 & $\mathrm{~F}$ & 4 \\
\hline 2 & 58 & $\mathrm{~F}$ & $\mathrm{~L}$ & 12.1 & 80 & $\mathrm{~F}$ & 7 & 63 & $\mathrm{~F}$ & $\mathrm{~L}$ & 14.6 & 90 & $\mathrm{~F}$ & 7 \\
\hline 4 & 64 & $\mathrm{~F}$ & $\mathrm{~L}$ & 36.7 & 100 & $\mathrm{~F}$ & 7 & 62 & $\mathrm{~F}$ & $\mathrm{~L}$ & 20.8 & 80 & $\mathrm{~F}$ & 7 \\
\hline 18 & 64 & $\mathrm{~F}$ & $\mathrm{R}$ & 16.3 & 90 & $M$ & 7 & 68 & $\mathrm{~F}$ & $\mathrm{R}$ & 22.9 & 90 & $M$ & 7 \\
\hline 9 & 46 & $\mathrm{~T}$ & L & 160.0 & 70 & $\mathrm{~F}$ & 7 & 43 & $\mathrm{~T}$ & $\mathrm{~L}$ & 135.5 * & 70 & $\mathrm{~F}$ & 7 \\
\hline \multicolumn{15}{|c|}{ Incomplete match in one criterion ${ }^{f}$} \\
\hline 6 & 50 & $\mathrm{~F}$ & $\mathrm{R}$ & 27.0 & 90 & $M$ & 7 & 54 & $\mathrm{~F}$ & $\mathrm{R}$ & 28.8 & 80 & $M$ & 5 \\
\hline 13 & 50 & $\mathrm{~F}$ & $\mathrm{R}$ & 1.4 & 90 & $M$ & 4 & 46 & $\mathrm{~F}$ & $\mathrm{R}$ & 0.7 & 100 & $M$ & 3 \\
\hline 3 & 50 & $\mathrm{~T}$ & $\mathrm{~L}$ & 45.4 & 70 & $M$ & 4 & 55 & $\mathrm{~T}$ & $\mathrm{~L}$ & 44.8 & 80 & $M$ & 7 \\
\hline 14 & 62 & $\mathrm{~T}$ & $\mathrm{~L}$ & 9.6 & 100 & $M$ & 7 & 59 & $\mathrm{~T}$ & $\mathrm{~L}$ & 10.0 & 100 & $M$ & 4 \\
\hline 15 & 64 & $\mathrm{~F}$ & $\mathrm{R}$ & 2.0 & 90 & $\mathrm{~F}$ & 7 & 65 & $\mathrm{~F}$ & $\mathrm{R}$ & 3.1 & 100 & $\mathrm{~F}$ & 4 \\
\hline 8 & 69 & $\mathrm{~F}$ & $\mathrm{R}$ & 20.9 & 70 & M & 4 & 65 & $\mathrm{~F}$ & $\mathrm{R}$ & 24.5 * & 80 & $M$ & 6 \\
\hline 1 & 49 & $\mathrm{~F}$ & $\mathrm{~L}$ & 31.7 & 90 & $M$ & 7 & 40 & $\mathrm{~F}$ & $\mathrm{~L}$ & 81.3 & 80 & $M$ & 7 \\
\hline 19 & 35 & $\mathrm{~T}$ & $\mathrm{~L}$ & 7.5 & 90 & $\mathrm{~F}$ & 6 & 33 & $\mathrm{~T}$ & $\mathrm{~L}$ & 10.8 & 50 & $\mathrm{~F}$ & 6 \\
\hline 5 & 44 & $\mathrm{~F}$ & $\mathrm{~L}$ & 33.1 & 80 & $M$ & 7 & 46 & $\mathrm{~F}$ & $\mathrm{~L}$ & 36.9 & 60 & $M$ & 7 \\
\hline 11 & 74 & $\mathrm{~F}$ & $\mathrm{~L}$ & 3.8 & 60 & $M$ & 7 & 74 & $\mathrm{~F}$ & $\mathrm{~L}$ & 8.0 & 100 & M & 7 \\
\hline \multicolumn{15}{|c|}{ Incomplete match in two criteria ${ }^{£}$} \\
\hline 16 & 65 & $\mathrm{~T}$ & L & 4.9 & 70 & $\mathbf{F}$ & 7 & 62 & $\mathrm{~T}$ & $\mathrm{~L}$ & 7.9 & 80 & M & 6 \\
\hline 10 & 48 & $\mathrm{~T}$ & $\mathrm{~L}$ & 106.0 & 70 & M & 7 & 51 & $\mathrm{~T}$ & $\mathrm{~L}$ & 98.0 * & 100 & M & 6 \\
\hline 12 & 78 & $P$ & $\mathrm{~L}$ & 17.6 & 90 & $M$ & 6 & 80 & $P$ & $\mathrm{~L}$ & 24.3 & 100 & $F$ & 5 \\
\hline
\end{tabular}

Lobe: F: Frontal; P: Parietal; T: Temporal.

Side: L: Left; R: Right.

Sex: F: Female; KPS: Karnofsky Performance Status; M: Male.

${ }^{£}$ Imperfectly matched criteria are shown in bold type.

* No contrast enhancement, tumor volume on Fluid Attenuated Inversion Recovery sequence.

Table 2. Characteristics of the patients under study. 


\begin{tabular}{|c|c|c|c|c|c|c|}
\hline \multirow[t]{2}{*}{ Parameters } & & \multicolumn{2}{|c|}{$\begin{array}{l}\text { Metastasis } \\
\text { group }\end{array}$} & \multicolumn{2}{|c|}{ Control group } & \multirow[t]{2}{*}{ p-value } \\
\hline & & $\mathrm{n}$ & & $\mathbf{n}$ & & \\
\hline \multicolumn{7}{|l|}{ Characteristic at surgery } \\
\hline \multirow[t]{2}{*}{ Sex } & Male & 12 & 60 & 11 & 55 & 0.589 \\
\hline & Female & 8 & 40 & 9 & 45 & \\
\hline Age (year) & Mean \pm SD (Range) & \multicolumn{2}{|c|}{$55.6 \pm 11.4$} & \multicolumn{2}{|c|}{$55.8 \pm 11.8$} & 0.924 \\
\hline \multirow{8}{*}{$\begin{array}{l}\text { Oncological treatment before } \\
\text { surgery }\end{array}$} & No & 6 & 30 & 17 & 85 & $<0.001$ \\
\hline & Yes & 14 & 70 & 3 & 15 & \\
\hline & Previous surgery of the lesion & 2 & & 1 & & \\
\hline & Radiotherapy & 10 & & 2 & & \\
\hline & Stereotactic radiotherapy & 8 & & & & \\
\hline & Conformational radiotherapy & & & 2 & & \\
\hline & Whole brain radiotherapy & 2 & & & & \\
\hline & Chemotherapy & 12 & & 1 & & \\
\hline \multirow[t]{2}{*}{ Increased intracranial pressure } & No & 19 & 95 & 19 & 95 & 1.0 \\
\hline & Yes & 1 & 5 & 1 & 5 & \\
\hline \multirow[t]{5}{*}{ Focal neurological deficit } & No & 9 & 45 & 11 & 55 & 0.527 \\
\hline & Yes & 11 & 55 & 9 & 45 & \\
\hline & Weakness/paresis & 4 & & & & \\
\hline & Language disturbances & 6 & & & & \\
\hline & Sensory disturbances & 1 & & & & \\
\hline \multirow[t]{2}{*}{ Cognitive evaluation } & No & 2 & 10 & 1 & 5 & 0.545 \\
\hline & Yes & 18 & 90 & 19 & 95 & \\
\hline \multirow[t]{3}{*}{ Cognitive deficit * } & No & 4 & 20 & 3 & 15 & 0.617 \\
\hline & Yes & 14 & 70 & 16 & 80 & \\
\hline & Not evaluated & 2 & 10 & 1 & 5 & \\
\hline \multirow[t]{2}{*}{ Epileptic seizure } & No & 10 & 50 & 3 & 15 & 0.016 \\
\hline & Yes & 10 & 50 & 17 & 85 & \\
\hline \multirow[t]{2}{*}{ Seizure control ${ }^{£}$} & No & 3 & 30 & 4 & 23.5 & 0.589 \\
\hline & Yes & 7 & 70 & 17 & 76.5 & \\
\hline \multirow[t]{3}{*}{ KPS score } & Mean \pm SD (Range) & \multicolumn{2}{|c|}{$81.5 \pm 16.4$} & \multicolumn{2}{|c|}{$81.5 \pm 10.4$} & 0.232 \\
\hline & 70 and $>$ & 19 & 95 & 17 & 85 & 0.292 \\
\hline & $<70$ & 1 & 5 & 3 & 15 & \\
\hline \multirow[t]{3}{*}{ Main lobar location } & Frontal & 10 & 50 & 11 & 55 & 0.875 \\
\hline & Temporal & 7 & 35 & 7 & 35 & \\
\hline & Parietal & 3 & 15 & 2 & 10 & \\
\hline \multirow[t]{2}{*}{ Side } & Left & 15 & 75 & 15 & 75 & 1.0 \\
\hline & Right & 5 & 25 & 5 & 25 & \\
\hline Tumor volume $\left(\mathrm{cm}^{3}\right)$ & Mean \pm SD (Range) & \multicolumn{2}{|c|}{$21.9 \pm 40.7$} & \multicolumn{2}{|c|}{$21.7 \pm 20.0$} & 0.107 \\
\hline \multicolumn{7}{|l|}{ Characteristic after surgery } \\
\hline \multirow[t]{4}{*}{ Histopathology } & Lung & 8 & 40 & $11 \|$ & wildty & astomas \\
\hline & Melanoma & 2 & 10 & 5 ID & utant & \\
\hline & Gastrointestinal tract & 1 & 5 & o & ? & trosytomac \\
\hline & Kidney & 1 & 5 & & - & 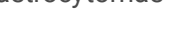 \\
\hline
\end{tabular}

Page 8/13 


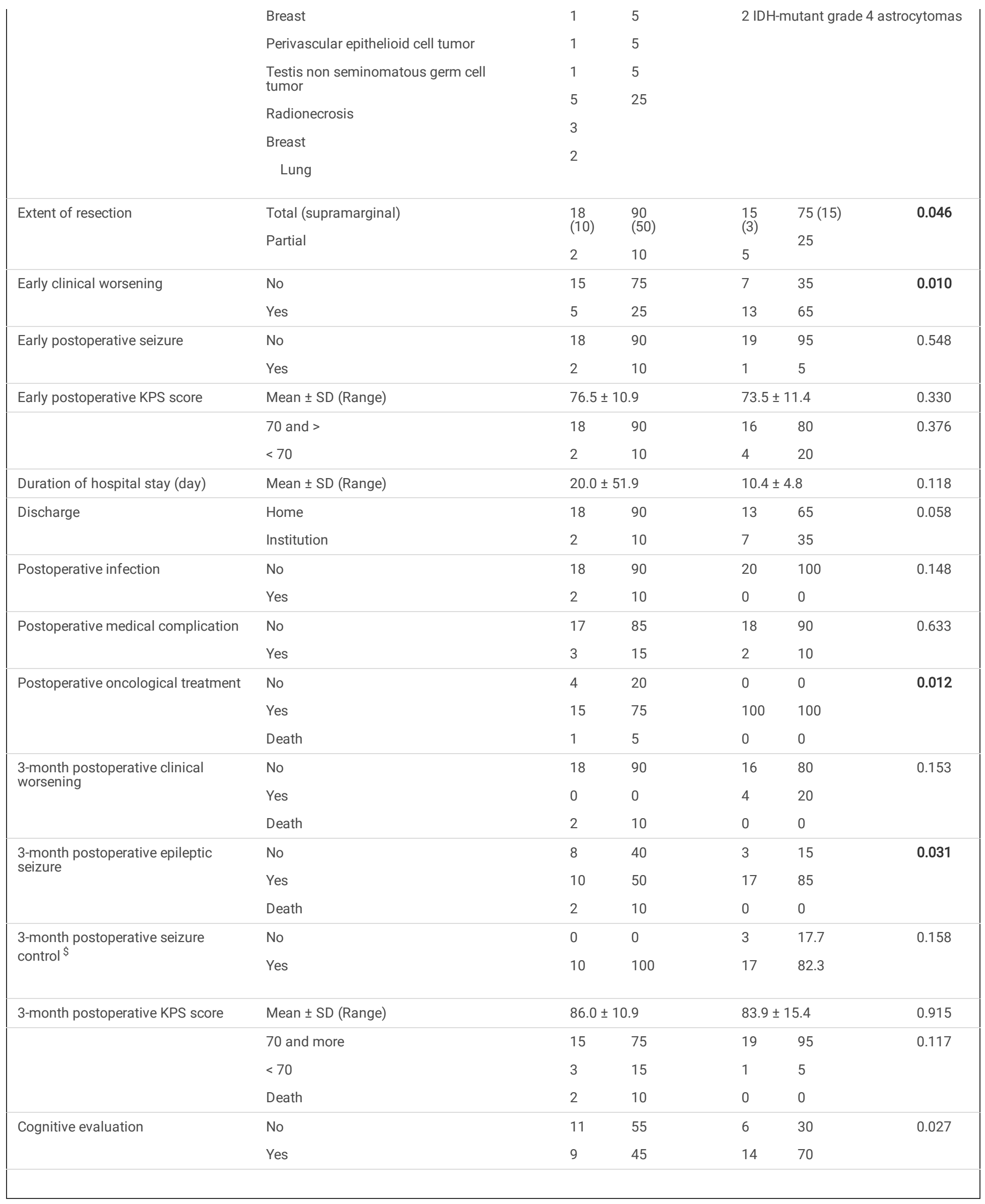

IDH: Isocitrate Dehydrogenase; KPS: Karnofsky Performance Status; SD: Standard Deviation.

${ }^{*}$ Cognitive deficits are detailed in Table 5. 
${ }^{£}$ In patients with seizures at the time of surgery.

$\$$ In patients with seizures after surgery.

Table 3. Intraoperative characteristics.

\begin{tabular}{|c|c|c|c|c|c|c|}
\hline Parameters & & \multicolumn{2}{|c|}{ Metastasis group } & \multicolumn{2}{|c|}{ Control group } & p-value \\
\hline \multicolumn{7}{|l|}{ Intraoperative characteristics } \\
\hline Overall duration of the surgery (min) & Mean \pm SD (Range) & \multicolumn{2}{|c|}{$181.2 \pm 34.7$} & \multicolumn{2}{|c|}{$237.6 \pm 38.2$} & $<0.001$ \\
\hline Duration of the awake phase (min) & Mean \pm SD (Range) & \multicolumn{2}{|c|}{$63.2 \pm 23.3$} & \multicolumn{2}{|c|}{$96.4 \pm 18.2$} & $<0.001$ \\
\hline \multirow{2}{*}{ Current intensity for functional mapping (mA) } & $3 \mathrm{~mA}$ and $<$ & 9 & 45 & 9 & 45 & 1.0 \\
\hline & $>3 \mathrm{~mA}$ & 10 & 55 & 10 & 55 & \\
\hline \multirow[t]{2}{*}{ Awake procedure abortion } & No & 20 & 100 & 20 & 100 & 1.0 \\
\hline & Yes & 0 & 0 & 0 & 0 & \\
\hline \multirow[t]{2}{*}{ Postural pain } & No & 18 & 90 & 18 & 90 & 1.0 \\
\hline & Yes & 2 & 10 & 2 & 10 & \\
\hline \multirow[t]{2}{*}{ Intraoperative seizure } & No & 20 & 100 & 19 & 95 & 0.311 \\
\hline & Yes & 0 & 0 & 1 & 5 & \\
\hline
\end{tabular}

SD: Standard Deviation.

Table 4. Clinical, epileptic seizure, and cognitive status before and after awake surgery. 


\begin{tabular}{|c|c|c|c|c|c|c|c|c|c|c|c|c|}
\hline \multirow[t]{2}{*}{ Pt. } & \multirow{2}{*}{$\begin{array}{l}\text { Tumor } \\
\text { location }\end{array}$} & \multirow[t]{2}{*}{ Handedness } & \multicolumn{3}{|c|}{ KPS status } & \multicolumn{3}{|c|}{ Epileptic seizure status } & \multicolumn{4}{|c|}{ Preoperative cognitive evaluation } \\
\hline & & & Preop & Postop & Post/pre & Preop & Postop & Post/pre & $\begin{array}{l}\text { Language } \\
\text { function }\end{array}$ & $\begin{array}{l}\text { Executive } \\
\text { function }\end{array}$ & $\begin{array}{l}\text { Memory } \\
\text { function }\end{array}$ & $\begin{array}{l}\text { Attent } \\
\text { functi }\end{array}$ \\
\hline 1 & $\begin{array}{l}\mathrm{L} \text {, middle } \\
\text { frontal gyrus }\end{array}$ & $\mathrm{R}$ & 90 & 100 & k & No seizure & $\begin{array}{l}\text { No } \\
\text { seizure }\end{array}$ & $=$ & Normal & Normal & Normal & Normi \\
\hline 2 & $\begin{array}{l}L \text {, inferior } \\
\text { frontal gyrus }\end{array}$ & $\mathrm{R}$ & 80 & 90 & k & Controlled & Controlled & $=$ & Normal & Altered & Altered & Normi \\
\hline 3 & $\begin{array}{l}\text { L, middle } \\
\text { and inferior } \\
\text { temporal gyri }\end{array}$ & $\mathrm{R}$ & 70 & Death & & Controlled & Death & & Altered & Altered & Altered & Normi \\
\hline 4 & $\begin{array}{l}L \text {, inferior } \\
\text { frontal gyrus }\end{array}$ & $\mathrm{R}$ & 80 & 80 & $=$ & No seizure & $\begin{array}{l}\text { No } \\
\text { seizure }\end{array}$ & $=$ & Altered & Altered & N/A & N/A \\
\hline 5 & $\begin{array}{l}\mathrm{R} \text {, superior } \\
\text { frontal gyrus }\end{array}$ & $\mathrm{R}$ & 80 & Death & & No seizure & Death & & Normal & Altered & Altered & Altere \\
\hline 6 & $\begin{array}{l}\mathrm{R} \text {, middle } \\
\text { frontal gyrus }\end{array}$ & L & 90 & 90 & $=$ & No seizure & $\begin{array}{l}\text { No } \\
\text { seizure }\end{array}$ & $=$ & Normal & Normal & Normal & Normi \\
\hline 7 & $\begin{array}{l}\text { L, post- } \\
\text { central gyrus }\end{array}$ & $\mathrm{R}$ & 80 & 100 & k & Controlled & Controlled & $=$ & Altered & Altered & Altered & Altere \\
\hline 8 & $\begin{array}{l}\mathrm{R} \text {, post- } \\
\text { central gyrus }\end{array}$ & $\mathrm{R}$ & 70 & 60 & $\mathrm{~m}$ & Controlled & Controlled & $=$ & Normal & Altered & Altered & Normi \\
\hline 9 & $\begin{array}{l}\text { L, superior } \\
\text { and middle } \\
\text { temporal } \\
\text { gyri, supra- } \\
\text { marginal } \\
\text { gyrus }\end{array}$ & $\mathrm{R}$ & 70 & 50 & $\mathrm{~m}$ & Controlled & Controlled & $=$ & Declined & & & \\
\hline 10 & $\begin{array}{l}\mathrm{R} \text {, supra- } \\
\text { marginal } \\
\text { gyrus }\end{array}$ & $\mathrm{R}$ & 70 & 70 & $=$ & No seizure & $\begin{array}{l}\text { No } \\
\text { seizure }\end{array}$ & $=$ & Normal & Altered & Normal & Normi \\
\hline 11 & $\begin{array}{l}\text { L, pre-central } \\
\text { gyrus }\end{array}$ & $\mathrm{R}$ & 60 & 60 & $=$ & Controlled & Controlled & $=$ & Emergency & & & \\
\hline 12 & $\begin{array}{l}\text { L, post- } \\
\text { central gyrus }\end{array}$ & $\mathrm{R}$ & 90 & 90 & $=$ & No seizure & $\begin{array}{l}\text { No } \\
\text { seizure }\end{array}$ & $=$ & Normal & Altered & Normal & Altere \\
\hline 13 & $\begin{array}{l}\text { R, pre- } \\
\text { central gyrus }\end{array}$ & $\mathrm{R}$ & 90 & 90 & $=$ & Uncontrolled & Controlled & k & Normal & Altered & Normal & Altere \\
\hline 14 & $\begin{array}{l}\mathrm{L} \text {, superior } \\
\text { temporal } \\
\text { gyrus }\end{array}$ & $\mathrm{R}$ & 100 & 80 & $\mathrm{~m}$ & No seizure & $\begin{array}{l}\text { No } \\
\text { seizure }\end{array}$ & $=$ & Altered & Normal & Normal & Altere \\
\hline 15 & $\begin{array}{l}\mathrm{R} \text {, middle } \\
\text { frontal gyrus }\end{array}$ & $\mathrm{R}$ & 90 & 90 & $=$ & No seizure & $\begin{array}{l}\text { No } \\
\text { seizure }\end{array}$ & $=$ & Normal & Altered & Normal & Normi \\
\hline 16 & $\begin{array}{l}\mathrm{L} \text {, sup. } \\
\text { middle and } \\
\text { inferior } \\
\text { temporal gyri }\end{array}$ & $\mathrm{R}$ & 70 & 80 & k & Uncontrolled & Controlled & k & Altered & Normal & Altered & Normi \\
\hline 17 & $\begin{array}{l}\text { L, middle } \\
\text { temporal } \\
\text { gyrus }\end{array}$ & $\mathrm{R}$ & 90 & 100 & k & Controlled & Controlled & $=$ & Normal & Normal & Normal & Normi \\
\hline 18 & $\begin{array}{l}\mathrm{R}, \text { pre-central } \\
\text { gyrus }\end{array}$ & $\mathrm{R}$ & 90 & 100 & k & No seizure & $\begin{array}{l}\text { No } \\
\text { seizure }\end{array}$ & $=$ & Normal & Normal & Normal & Normi \\
\hline 19 & $\begin{array}{l}\text { L, } \\
\text { hippocampal } \\
\text { formation }\end{array}$ & $\mathrm{R}$ & 90 & 80 & $\mathrm{~m}$ & No seizure & $\begin{array}{l}\text { No } \\
\text { seizure }\end{array}$ & $=$ & Altered & Normal & Altered & Normi \\
\hline 20 & $\begin{array}{l}\text { L, post- } \\
\text { central gyrus }\end{array}$ & $\mathrm{R}$ & 80 & 100 & k & Uncontrolled & Controlled & k & Normal & Normal & Altered & Normi \\
\hline
\end{tabular}

KPS: Karnofsky Performance Status. $\mathrm{k}$ improved. = stable. $\mathrm{m}$ decreased.

D: Day; L: Left; R: Right.

Figures 


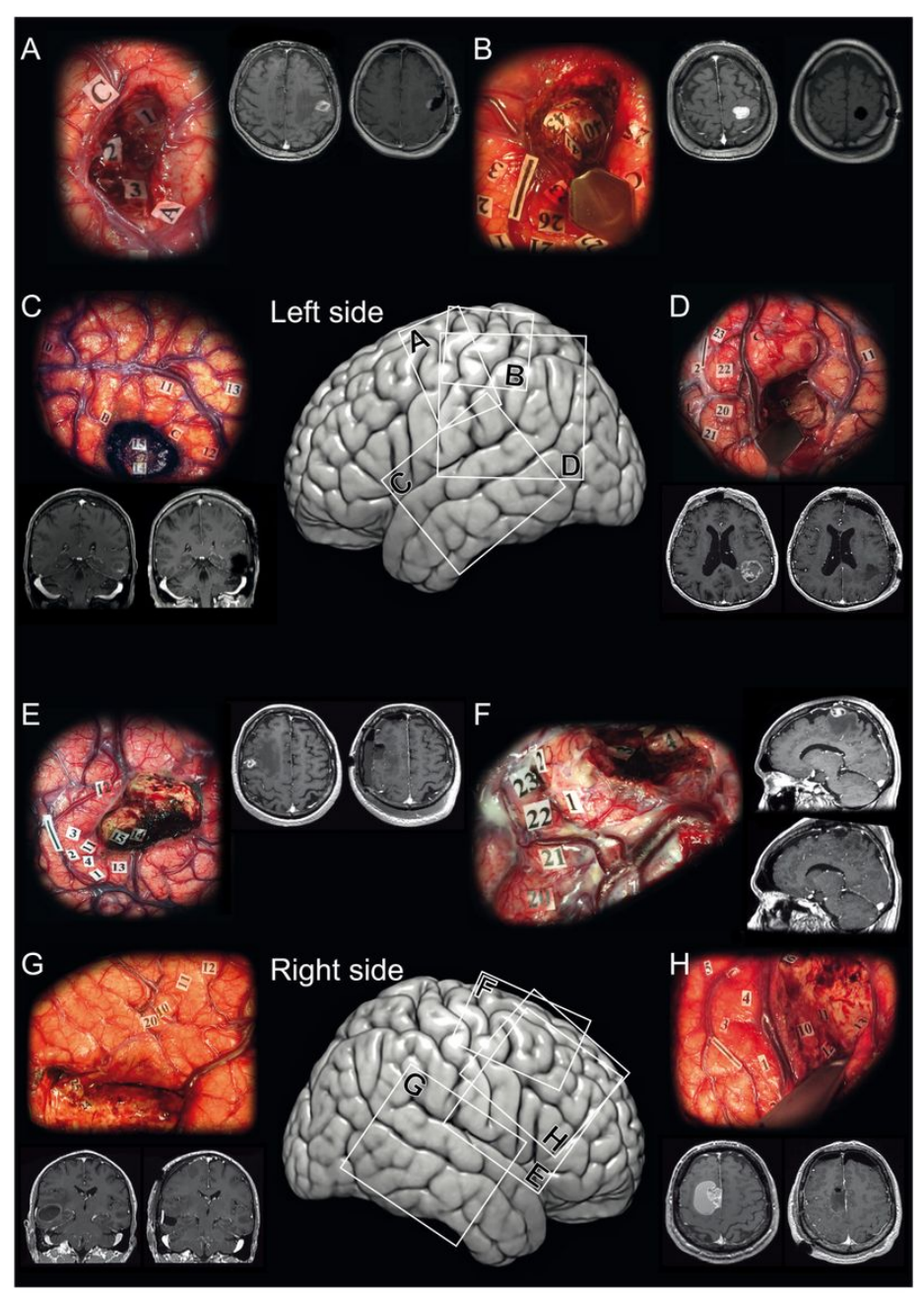

\section{Figure 1}

Illustrative cases of brain metastasis maximal safe functional-based resection using direct cortico-subcortical electric stimulation under awake conditions to define functional boundaries. Intraoperative photographs showing the surgical field with the functional boundaries of the resection marked intraoperatively by numbered tags in the depth of the cavity and corresponding preoperative and postoperative magnetic resonance examinations. A. Left fronto-central lung metastasis previously treated by stereotactic radiotherapy seven years ago discovered in a 74-year-old right-handed man presenting with epileptic seizures and right facial paresis (patient $n^{\circ} 11$ ). A partial resection was performed (numbered tags: involuntary movement of the face and mouth in 1,2 , and 3 identifying the primary motor subcortical pathways) and demonstrated a radionecrosis. B. Left parietal non-seminomatous germ cell testis tumor metastasis in a 43-year-old right-handed man presenting with epileptic seizures and right upper limb paresthesia (patient $n^{\circ} 20$ ). A total resection was performed (numbered tags: involuntary movement of the thumb in 1, involuntary movement of the wrist in 2, and involuntary movement of the elbow in 3 identifying the primary motor cortical pathways; paresthesia of the fingers in 21, 22, 23, and 26, paresthesia of the chest in 25, paresthesia of the thumb in 41 , and paresthesia of the lower limb 40, 42, 43 identifying sensory cortico-subcortical pathways). C. Left temporal gastrointestinal metastasis in a 52-year-old righthanded man found on MRI check-up while asymptomatic (patient ${ }^{\circ}{ }^{17}$ ). A supramarginal resection was performed (numbered tags: phonemic paraphasia in 11 , latency and semantic paraphasia in 12, semantic paraphasia in 13, and latency in 14 and 15 identifying language cortico-subcortical pathways). D. Left parietal renal cell carcinoma metastasis in a 78-year-old right-handed man found on MRI check-up while asymptomatic (patient $n^{\circ} 12$ ). A supramarginal resection was performed (numbered tags: involuntary movement of the mouth and tongue in 1, and involuntary movement of the hand in 2 identifying the primary motor cortical pathways; paresthesia of the mouth and tongue in 20 and 21, and paresthesia of the face in 22 and 23 identifying the sensory cortical pathways; semantic paraphasia in 11 and phonemic paraphasia in 12 identifying language cortico-subcortical pathways). E. Right fronto-central lung metastasis previously treated by stereotactic radiotherapy nine months ago discovered in a 50-year-old right-handed man found on MRI check-up while asymptomatic (patient $n^{\circ} 13$ ). A total resection was performed (numbered tags: vocalization in 1 and speech arrest in 4 identifying language cortical pathways; involuntary movement of the tongue in 2 and 3 identifying the primary motor cortical pathways; arrest of voluntary movements of the upper limb in $11,12,13,14$, and 15 identifying cortico-subcortical negative motor networks) and demonstrated a radionecrosis. F. Right fronto-central lung metastasis discovered in a 64-year-old right-handed man presenting with right lower limb paresis (patient $n^{\circ} 18$ ). A supramarginal resection was performed (numbered tags: involuntary movement of the chest in 1, involuntary movement of the hip in 2 and 3 , and involuntary movement of the of the foot in 4 identifying the primary motor cortico-subcortical pathways; 20 paresthesia of the wrist in 20, paresthesia of the shoulder in 21, paresthesia of the trunk in 22, and paresthesia of the hip in 23 identifying sensory cortico-subcortical pathways). G. Right tempo-parietal lung metastasis previously treated by whole brain radiation therapy six months ago discovered in a 48-year-old left-handed man presenting with language disturbances (patient $n^{\circ} 10$ ). A total resection was performed (numbered 
tags: hypophonia in 10, latency in 11, dysarthria in 12, and phonemic paraphasia in 20 identifying language cortical pathways; blurring of the visual field in 24 and 25 identifying the visual pathways). H. Right fronto-central melanoma metastasis discovered in a 50-year-old right-handed man presenting with left lower limb paresis (patient $n^{\circ} 5$ ). A supramarginal resection was performed (numbered tags: involuntary movement of the wrist in 1 and 2 , involuntary movement of the elbow in 3 and 4, involuntary movement of the shoulder in 5, and involuntary movement of the lower limb in 6 identifying the primary motor corticosubcortical pathways; arrest of voluntary movements of the upper limb in 10,11, 12, and 13, identifying subcortical negative motor networks; saccadic eye deviation in 13 identifying subcortical pathways underpinning eye movements).

\section{Supplementary Files}

This is a list of supplementary files associated with this preprint. Click to download.

- SupplementaryTable118112020.docx 